
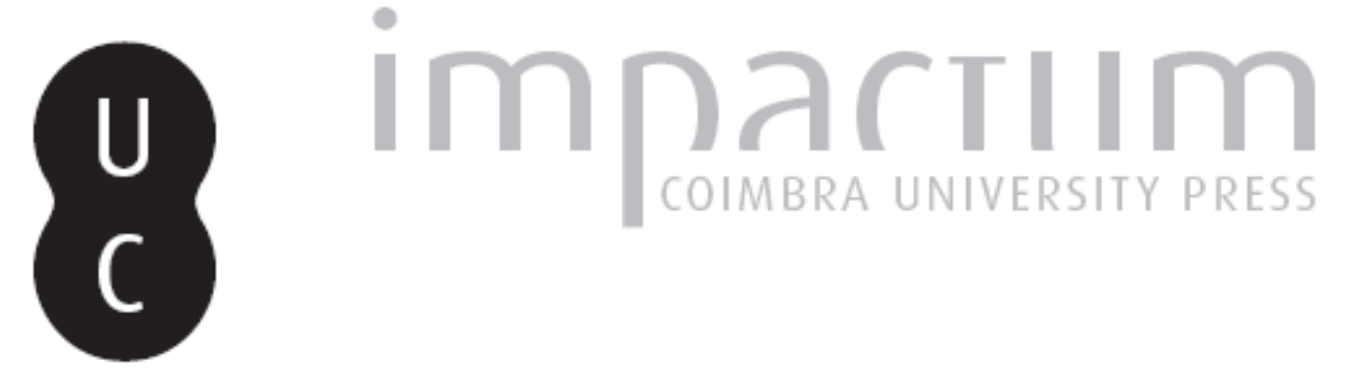

\title{
A arqueologia histórica em Laranjeiras (SE-Brasil): uma proposta de salvaguarda da cultura material portuguesa nas ruínas da cidade
}

\author{
Autor(es): $\quad$ Mello, Janaina Cardoso de
}

Publicado por: Centro de História da Sociedade e da Cultura

URL persistente:

URl:http://hdl.handle.net/10316.2/39486

DOI:

DOI:http://dx.doi.org/10.14195/1645-2259_11_12

Accessed : $\quad$ 26-Apr-2023 01:12:41

A navegação consulta e descarregamento dos títulos inseridos nas Bibliotecas Digitais UC Digitalis, UC Pombalina e UC Impactum, pressupõem a aceitação plena e sem reservas dos Termos e Condições de Uso destas Bibliotecas Digitais, disponíveis em https://digitalis.uc.pt/pt-pt/termos.

Conforme exposto nos referidos Termos e Condições de Uso, o descarregamento de títulos de acesso restrito requer uma licença válida de autorização devendo o utilizador aceder ao(s) documento(s) a partir de um endereço de IP da instituição detentora da supramencionada licença.

Ao utilizador é apenas permitido o descarregamento para uso pessoal, pelo que o emprego do(s) título(s) descarregado(s) para outro fim, designadamente comercial, carece de autorização do respetivo autor ou editor da obra.

Na medida em que todas as obras da UC Digitalis se encontram protegidas pelo Código do Direito de Autor e Direitos Conexos e demais legislação aplicável, toda a cópia, parcial ou total, deste documento, nos casos em que é legalmente admitida, deverá conter ou fazer-se acompanhar por este aviso.

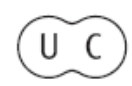




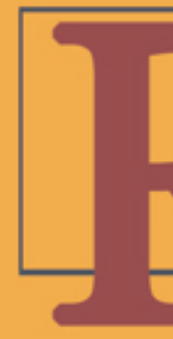

\section{evista de História} da Sociedade e da Cultura

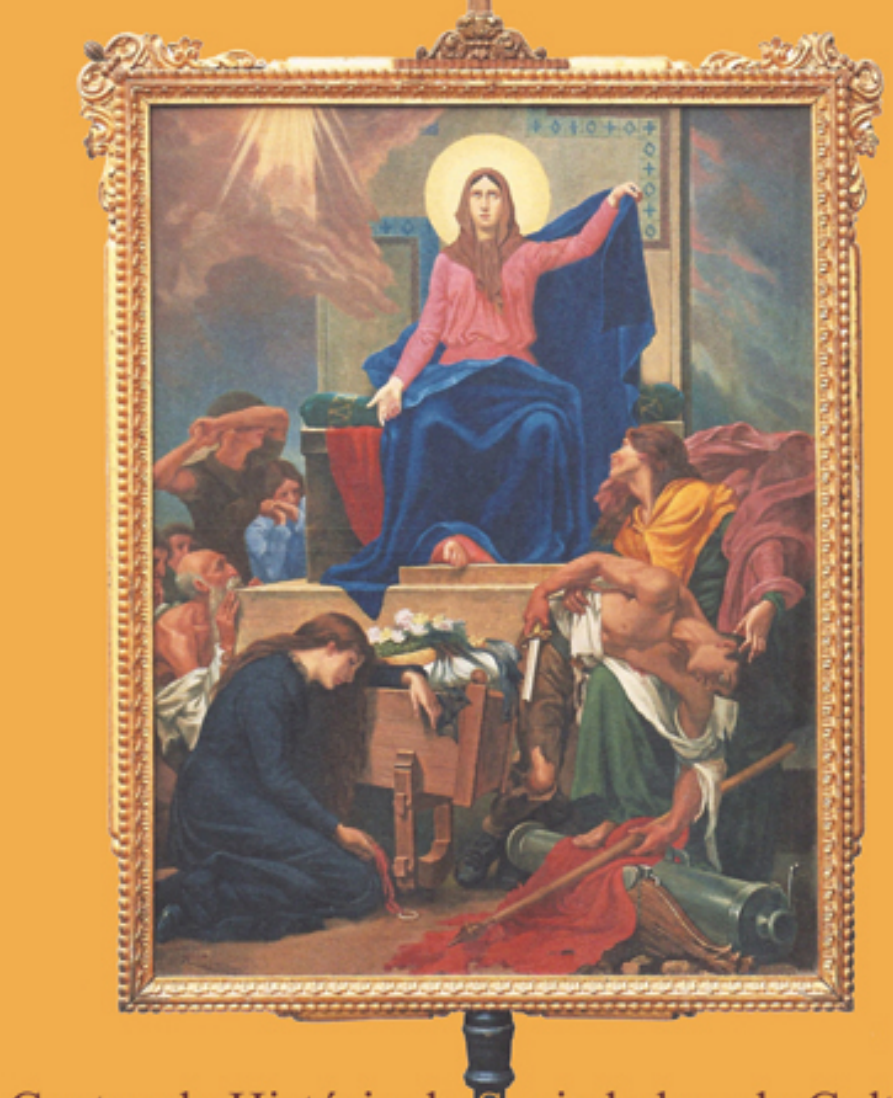

Centro de História da Sociedade e da Cultura Universidade de Coimbra 


\title{
A Arqueologia Histórica em Laranjeiras (SE-Brasil): uma proposta de salvaguarda da cultura material portuguesa nas ruínas da cidade
}

\author{
Janaina Cardoso de Mello \\ UFS (Universidade Federal de Sergipe) \\ Pesquisadora FAPITEC-SE/CNPq \\ janainamello@uol.com.br
}

Texto recebido em/ Text submitted on: 17/02/2011

Texto aprovado em/ Text approved on: 29/08/2011

\section{Resumo/Abstract:}

O artigo apresenta a necessidade de a arqueologia histórica no Brasil, ao voltar seu olhar para os contextos da época Moderna e Contemporânea, atuar na identificação, inventariação e salvaguarda do patrimônio cultural. Buscaremos enfatizar os elementos da cultura material portuguesa nas ruínas de antigas edificações na cidade de Laranjeiras (Sergipe), cujo ápice de sua economia ocorre ao longo do século XIX, com o domínio dos engenhos de açúcar, os ricos sobrados residenciais, os teatros e hospital local. Esse trabalho busca discutir a prospecção arqueológica para expor a historicidade da arquitetura urbana na formação de sua população, as heranças da colonização portuguesa nas ruínas, suas antigas funcionalidades, ações de consolidação e possibilidades de usos sociais desses locais nos dias atuais.

The article presents the need for historical archaeology in Brazil, when turning its look to the contexts of modern and contemporary times, to act in identifying, inventorying and safeguarding of cultural heritage. We will try to emphasize the elements of material culture in the ruins of old Portuguese buildings in the town of Laranjeiras (Sergipe), whose economic apex occurs throughout the 19th century, with dominance of sugar mills, the wealthy residential town homes, theaters and local hospital. This work seeks to discuss the archaeological prospecting to expose the historicity of urban architecture in the formation of its population, the heritage of Portuguese colonization in ruins, its ancient features, actions of consolidation and possibilities for social uses of those locations today.

Palavras chave/Keywords:

Ruínas; Herança portuguesa; Laranjeiras (SE-Brasil).

Ruins; Portuguese heritage; Laranjeiras (SE-Brazil). 


\section{Introdução}

O estilo aquitetônico adotado nas edificações de cidades históricas em Sergipe, situada ao nordeste do Brasil no século XVII, constituiu-se por um conjunto urbano marcado pela presença dos jesuítas e suas obras. Presença destacada na historiografia regional ao identificar-se que: "cedo vieram os jesuítas desdobrar a atividade de sua política em Sergipe [...] sob o duplo caráter de sacerdote e agricultor, assumem a direção espiritual da capitania e pedem também doações de terra"'.

O barroco colonial introduzido no Brasil pelos missionários religiosos portugueses mesclou-se as influências locais resultado do povoamento europeu, africano e indígena na região. Deve-se ainda considerar que a escassez de materiais e mão-de-obra especializada contribuiu para dar uma feição muito singular ao barroco brasileiro de características "mestiças".

Entre 1700 e 1759, são construídas residências para obras de evangelização no Vale do rio Contiguiba em Laranjeiras, compostas por uma casa-grande e uma capela chamada Retiro. Em 1731, é inaugurada a Igreja de Nossa Senhora da Conceição da Comandaroba, cujo o pórtico em pedra calcária possui o monograma A.M.D.G (Ad Majorem Dei Gloriam, 1734) 3

Todavia, é possível encontrar-se entre os bens materiais religiosos da cidade de Laranjeiras, a partir do século XVIII, uma transição estilística do barroco ao neoclassicismo ${ }^{4}$, que ao longo dos séculos XIX e XX assume a forma do ecletismo ${ }^{5}$.

1 FREIRE, Felisbelo - História de Sergipe. Petrópolis: Vozes; Aracaju: Governo do Estado de Sergipe, 1977, p. 94.

2 SEVCENKO, Nicolau - Pindorama revisitada: cultura e sociedade em tempos de virada. Série Brasil cidadão. Editora Peirópolis, 2000. pp. 39-47.

3 OLIVEIRA, Filadelfo Jônatas - Registro dos fatos históricos de Laranjeiras. Aracaju: Governo de Sergipe; Secretaria da Cultura, 2005, pp. 52-54.

${ }^{4}$ A arquitetura neoclássica caracteriza-se pela busca da nobreza e racionalidade da arquitetura greco-romana da Antiguidade. A harmonia é buscada usando os motivos clássicos: pórticos com colunatas, uso das ordens gregas, simetria na composição, regularidade nas aberturas e frontões triangulares. A decoração é contida, distante dos "exageros" barrocos e rococós. Ver. GONTAR, Cybele - Neoclassicism. In: Heilbrunn Timeline of Art History. New York: The Metropolitan Museum of Art, 2000.

5 O ecleticismo é a mistura de estilos arquitetônicos do passado para a criação de uma nova linguagem arquitetônica. Apesar de que sempre há existido alguma mistura de estilos durante a história da arquitetura, o termo arquitetura eclética é usado em referência aos estilos 
Nas décadas de 1960 e 1970, buscou-se o retorno ao "lugar de origem" para fundamentar a identidade nacional brasileira, assim o barroco brasileiro passa a despertar grande interesse entre os pesquisadores e se torna reconhecido além das fronteiras ${ }^{6}$.

Essa atração pelo barroco não era um dado novo, pois já estava na pauta das discussões e ações dos orgãos de tombamento e proteção do patrimônio brasileiro desde 1936, quando o Serviço do Patrimônio Histórico e Artístico Nacional (SPHAN) utiliza o barroco como uma "categoria simbólica" de valoração do patrimônio arquitetônico no país.

O SPHAN detinha o poder de fiscalizar, executar obras de conservação ou restauro, a construção de edificações na vizinhança, definição de infra-estrutura, parcelamento do solo, os quais eram analisados segundo critérios internos dos órgãos, ou seja, caso a caso, sem que houvesse um estímulo à participação dos proprietários ou agentes privados na preservação de bens tombados; importando, sobretudo, a manutenção da integridade física e estilística dos bens imóveis tombados?

A ausência de uma ação estatal de apoio financeiro á conservação dos bens imóveis em Laranjeiras terminou por resultar na degradação física de muitos prédios, mesmo tendo sido a área central da cidade tombada pelo Instituto do Patrimônio Histórico e Artístico Nacional (IPHAN, ex-SPHAN). A deterioração das obras provocada pelo tempo, intempéries climáticas (enchentes do rio Contiguiba) e descaso do poder público e/ou privado legou ao presente um passado em ruínas.

surgidos durante o século XIX que exibiam combinações de elementos que podiam vir da arquitetura clássica, medieval, renascentista, barroca e neoclássica.

6 HANSEN, João Adolfo - Barroco Brasileiro, Petit Palais \& Ruína In: PRADO, Maria Lígia Coelho; VIDAL, Diana Gonçalves - À margem dos 500 anos: reflexões irreverentes. Volume 7 de Estante USP-Brasil 500 anos. São Paulo: EdUSP, 2002.

7 FREITAS apud NOGUEIRA, Adriana Dantas - Patrimônio arquitetônico e história urbana. Ensaios sobre o patrimônio arquitetônico de Sergipe e sobre a estrutura sócio-espacial de Aracaju. São Cristóvão: EDUFS; Aracaju”Oviêdo Teixeira, 2006, p. 101. [grifo da autora] 
Longe de adentrar a seara de discussões teóricas nacionais e internacionais a respeito do campo disciplinar arqueológico, a análise aqui contida parte da premissa da arqueologia histórica, apontada por Funari ${ }^{8}$ como um estudo das sociedades com escrita relacionado a construção de suas identidades, e que nas palavras de Charles Orser Jr. possui: “[...] seu foco de atenção no passado recente ou moderno, um passado que incorporou muitos processos, perspectivas e objetos materiais que ainda estão sendo usados em nossos dias".

Leva-se em consideração as potencialidades das ruínas de Laranjeiras como objeto de estudo para as pesquisas da arqueologia histórica apartir da "noção de significância", ou seja, dos aspectos históricos, científicos, étnicos, públicos e legais contidos nesse espaço ${ }^{10}$.

Destaca-se o papel primordial da arqueologia histórica ao tratar as relações sociais dos indivíduos, para compreender a cultura material como fonte de informação sobre os vários grupos sociais distintos em sua multiplicidade de vozes (aparentes ou esquecidas) imiscuídas nos vestígios físicos que constroem um discurso narrativo e interpretativo sobre um determinado espaço ${ }^{11}$.

\section{Cidade, ruínas e herança portuguesa em Laranjeiras (SE)}

A cidade brasileira como centro habitacional na vida cotidiana é tardia em sua historicidade, pois enquanto parte integrante do Império ultramarino português, somente no século XVIII cidades como Salvador e Recife exerceram sua influência sobre a aristocracia agrária para que esta viesse

8 FUNARI, Pedro Paulo - Os Avanços da Arqueologia histórica no Brasil, um Balanço. (2003) In: www.comciencia.br/reportagens/arqueologia/arq13.shtml (20/01/ 2011).

9 ORSER Jr., C.E - Introdução à Arquologia Histórica. Belo Horizonte: Oficina de Livros, 1992, p. 28.

${ }^{10}$ STASKI apud TOCCHETTO, Fernanda; THIESEN, Beatriz - A memória fora de nós. A preservação do patrimônio arqueológico em áreas urbanas. In: LIMA, Tânia Andrade (Org.) - Revista do Patrimônio Histórico e Artístico Nacional. Patrimônio Arqueológico: o desafio da preservação. $\mathrm{N}^{\circ}$ 33. Brasília: IPHAN, 2007, p. 270.

${ }^{11}$ HODDER; TILLEY apud MARTIN, Ann Stuart - Material things and cultural meaning: notes on the study of early American culture. The William and Mary Quaterly, 53(1). Material Culture in Early America, 1996, pp. 7-8. 
aceitar a experiência urbana. Na América Portuguesa a relação agricultura-exportação conduzia o modus vivandi de uma sociedade composta por brancos portugueses e de outras nacionalidades, índios e negros, a configurar uma forte miscigenação demográfica. Ao mesmo tempo, as obras arquitetônicas personificadas em catedrais, igrejas, prédios de ordens religiosas, palácios, casas, moradias dos mais diversos estilos, de origem européia, possuíam também marcas da mestiçagem resultante desse encontro multi-étnico.

Os centros históricos passaram a representar o traçado inicial da cidade, a compor estruturas urbanas e arquitetônicas que expressam as manifestações políticas, econômicas, sociais, culturais e tecnológicas, das formações culturais dos diferentes períodos históricos, por meio dos quais evoluíram, estruturas unitárias ou fragmentárias, ainda que tenham se transformado ao longo do tempo e se apresentem como testemunhos de civilizações passadas ${ }^{12}$.

Desde sua origem, os centros históricos ocupam uma função residencial, ou seja, abrigam homens, mulheres e crianças que habitam esse espaço enquanto palco permanente para suas atividades de descanso, lazer e serviços em geral, ligados aos hábitos e práticas de uma cultura própria a cada grupo social do local.

A arquitetura residencial é a testemunha viva das manifestações sociais e culturais das gerações anteriores e daqueles que ocupam esse espaço na atualidade. Assim: "o patrimônio arquitetônico é um capital espiritual, cultural, econômico e social cujos valores são insubstituíveis"13.

Rogério Proença Leite ${ }^{14}$ percebeu em seus estudos que nas últimas décadas do século XX houve significativas mudanças no valor dos bens simbólicos preservados, a refazer o próprio conceito de patrimônio dentro de uma concepção mais fluida que implica em práticas voltadas para o consumo dos lugares. O desenvolvimento urbano ao atuar como um agente

${ }^{12}$ SALCEDO, Rosío Fernandez Baca - A reabilitação da residência nos centros históricos da América Latina. Cusco (Peru) e Ouro Preto (Brasil). São Paulo: EDUNESP, 2007, p. 15.

${ }^{13}$ CONSELHO DA EUROPA - Manifesto de Amsterdã: Carta Européia. INSTITUTO DO PATRIMÔNIO HISTÓRICO E ARTÍSTICO NACIONAL - Cartas patrimoniais (Caderno de documentos $n^{\circ}$ 3). Brasília: IPHAN,1995, p. 246.

${ }^{14}$ LEITE, Rogério Proença - Contra-usos da cidade. Lugares e espaço público na experiência urbana contemporânea. Campinas: EDUNICAMP, 2006, p. 47. 
estruturador dos big business, ou seja, na comercialização da "cidade-patrimônio", ganha força no turismo e/ou na especulação imobiliária.

A cidade de Laranjeiras, localizada no Estado de Sergipe (Brasil) a aproximadamente $20 \mathrm{~km}$ de Aracaju, iniciou seu processo de estruturação no século XVIII, tendo surgido às margens do rio Cotinguiba onde havia um pé de laranjeira, sob o qual os viajantes descansavam a se proteger do sol e entoar canções românticas até que chegasse o momento de se por na estrada novamente. Para além das versões poéticas, a certeza é que a cidade se tornou uma das principais cidades comerciais de Sergipe Del Rey, a obter da produção da canavieira sua principal renda ${ }^{15}$.

Em 1850 Sergipe, possuía um total de 726 engenhos, sendo que 72 estavam em Laranjeiras. Por isso, em 1874 a população escrava em Sergipe representava $19,1 \%$ da população total, um dos maiores percentuais da região nordeste ${ }^{16}$.

Esse alto investimento em mão de obra escrava direcionada ao cultivo da cana-de-açúcar, embora a tecnologia aplicada fosse bem rudimentar, encontra uma particularidade na região da Cotinguiba e especialmente em Laranjeiras, uma vez que de acordo com Resende e Guimarães:

[...] a fertilidade natural da terra pela sua formação geológica contribuiu em muito para o não esgotamento das mesmas, o que não ocorreu em outras províncias brasileiras e regiões sergipanas ${ }^{17}$.

Nesse contexto, imponentes habitações, famosas na descrição do historiador pernambucano Gilberto Freire ${ }^{18}$, conhecidas como "Casas Grandes" ocupavam vasta extensão territorial a possuir em anexo capelas dedicadas a

${ }^{15}$ SILVA, Eder Donizeti da; NOGUEIRA, Adriana Dantas - Lançando um olhar sobre o patrimônio arquitetônico de Laranjeiras. In: NUNES, Verônica Maria Meneses; NOGUEIRA, Adriana Dantas (Orgs.) - O despertar do conhecimento na colina azulada. A Universidade Federal de Sergipe em Laranjeiras. Vol. 1. $2^{\text {a }}$ Ed. São Cristóvão: EDUFS, 2009, p. 40.

${ }^{16}$ FIGUEIREDO, Ariosvaldo - O negro e a violência do branco: o negro em Sergipe. Rio de Janeiro, J. Álvaro Editor, 1977, p. 33.

${ }^{17}$ RESENDE, José Mário dos Santos; GUIMARÃES, Joselita Maria dos Santos - A Geografia da Propriedade de Terras e das Técnicas Agrícolas na Imperial Cidade de Laranjeiras /SE (1850-1888). Revista da Fapese, v.3, n.1, p. 139-164, jan./jun. 2007, p. 157.

${ }^{18}$ FREIRE, Gilberto - Casa Grande \& Senzala. Rio de Janeiro: Global, 2005. 
um santo padroeiro da fazenda, bem como as senzalas a abrigar os cativos africanos trazidos de além mar para o trabalho nas plantações de açúcar.

Assim foi com o sítio Santa Anna, cuja propriedade no século XIX fora de Francisco Alves da Motta, pertencendo hoje a família Ribeiro Guimarães, e a conservar na atualidade as ruínas do antigo sobrado (fig. 1), da senzala e da Capela Sant'Aninha que remonta aos tempos de opulência da região.

\section{Imagem 1 - Ruínas da Casa Grande do sítio Santa Anna em Laranjeiras,} às margens do rio Contiguiba.

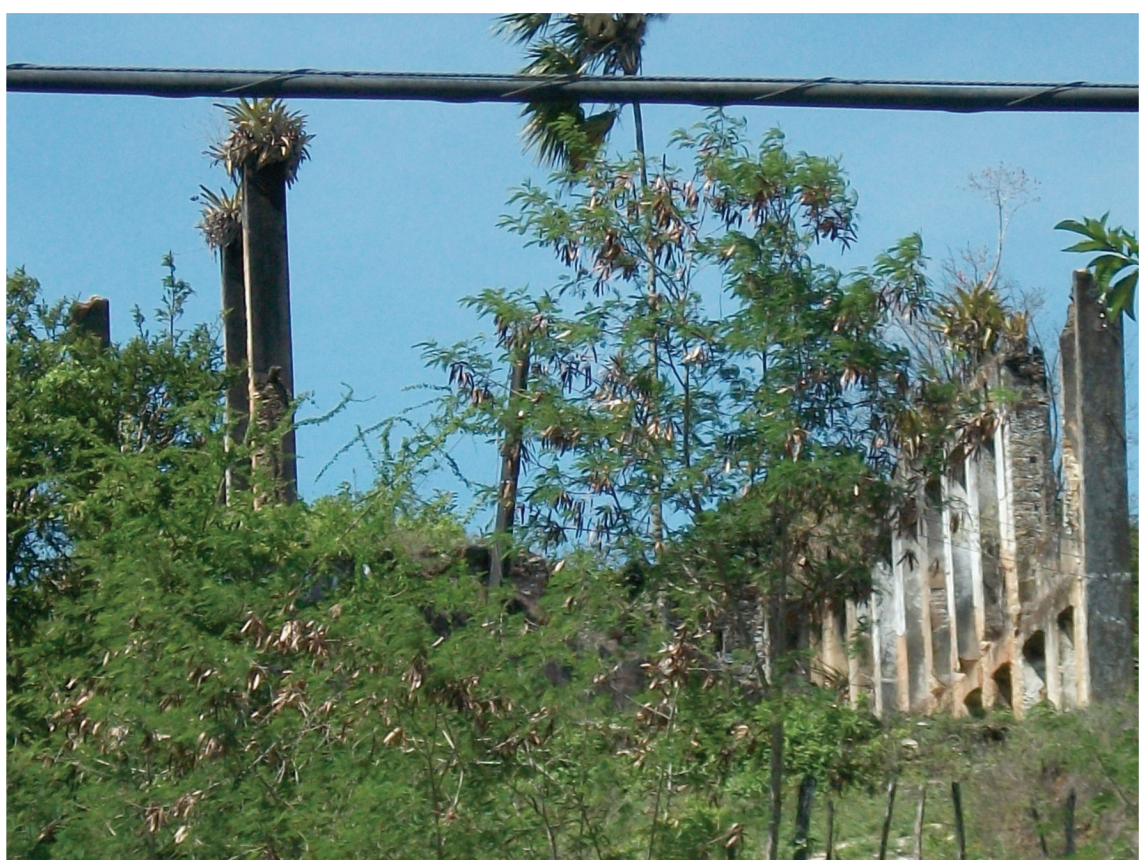

Fonte: Foto de Janaina Cardoso de Mello (Laranjeiras - SE/Brasil, 24/01/2011)

A Capela Sant'Aninha (fig. 2) construída em 1860 no local onde havia um depósito de pólvora, na zona rural de Laranjeiras, à margem esquerda do rio Contiguiba, foi erguida pela devoção da filha do proprietário à Nossa Senhora da Conceição. Sua arquitetura imponente e eclética é demarcada por sua cúpula de inspiração romana e suas duas sineiras (torres falsas), ambas com sinos de cobre, indicando pestígio social e poder econômico. Considerada uma das capelas particulares mais ricas do nordeste por possuir em seu interior detalhes ornados em ouro maciço e também minúcias 
em tapeçaria antiga. Em 1875 foi reformada e transformada também em necrópole, sendo inaugurada em 12 de fevereiro de $1878^{19}$.

\section{Imagem 2 - Capela Sant'Aninha}

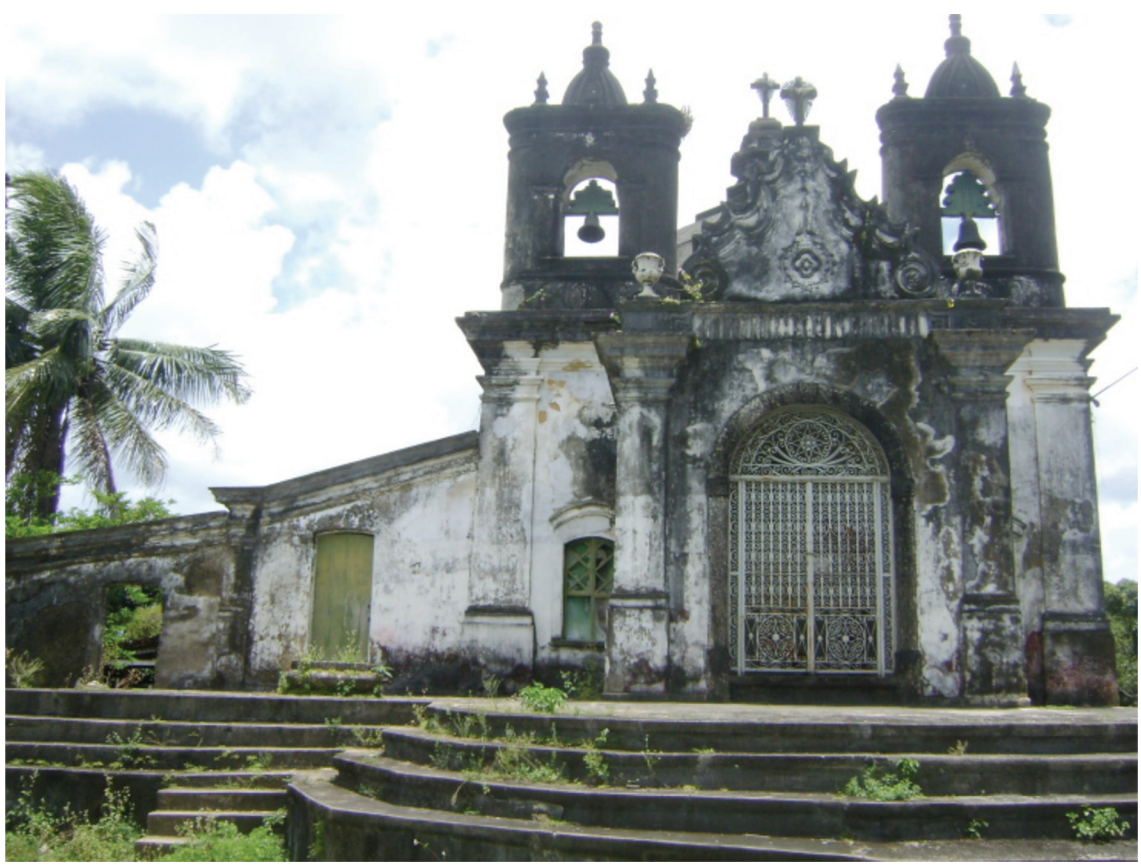

Fonte: Foto de Loíze Raquel (Laranjeiras, SE/Brasil - 10/11/2009)

Laranjeiras foi elevada a condição de Vila em 07 de agosto de 1832, mas em 1824 já era a povoação mais rica da província de Sergipe a possuir mais de sessenta engenhos de açúcar, fábricas de charutos e aguardentes e representações comerciais européias. Em 4 de maio de 1848 passou a condição de cidade. De acordo com Beatriz Góis Dantas ${ }^{20}$, com a instalação da Alfândega de Sergipe a localidade e a demografia se transformaram em "importante empório comercial para cuja feira 'concorriam comboios de quase todos os pontos da província' a comunicar-se diretamente com as capitais da Bahia, Rio de Janeiro e Pernambuco".

${ }^{19}$ SILVA, Eder Donizeti da; NOGUEIRA, Adriana Dantas - Lançando um olhar...cit, pp. 64-65.

${ }^{20}$ DANTAS, Beatriz Góis - A Taieira de Sergipe. Uma dança folclórica. Petrópolis: Vozes, 1972, p. 17. 
De 1878 a 1904, a cidade de Laranjeiras vivenciou o seu "período áureo", ostentando o título de "Atenas sergipana". O termômetro da efervescência cultural da cidade era balizado por dois grandes teatros: o Santo Antônio e o São Pedro.

O teatro Santo Antônio terminou por se sobressair ao São Pedro, cujas instalações não foram concluídas, a atrair a atenção de companhias nacionais e internacionais que apresentaram-se nesse espaço. Durante um bom tempo ficou abandonado, utilizado como cortiço, mas com um novo uso social após a restauração do projeto Monumenta ${ }^{21}$ ao abrigar a biblioteca e salas de professores do campus da Universidade Federal de Sergipe (UFS).

\section{Imagem 3 - Ruínas do Teatro São Pedro (parte externa)}

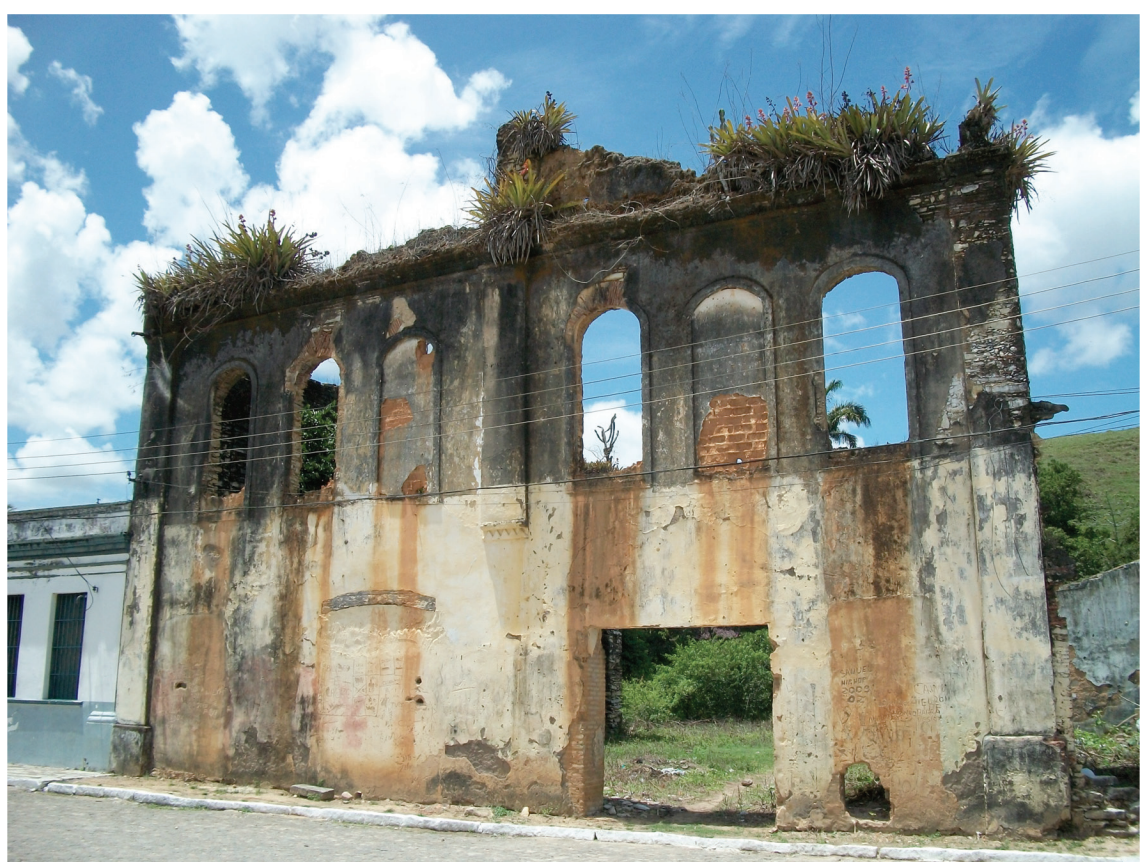

Foto de Janaina Cardoso de Mello (Laranjeiras - SE/Brasil, 24/01/2011)

${ }^{21}$ O Programa Monumenta foi um programa do governo federal brasileiro executado pelo Ministério da Cultura e patrocinado pelo Banco Interamericano de Desenvolvimento (BID) que consistiu na reforma e resgate do patrimônio cultural urbano em todo Brasil. Criado em 1995, atendeu mais de 26 cidades. 
O teatro possui de pé somente a fachada e parte de uma parede lateral. Sua arquitetura pode ser classificada como neoclássica ortodoxa, com tendências ao neocolonial tradicionalista ${ }^{22}$. Sua estrutura de sobrado conserva janelas e portas em arco. Não há nenhum impedimento a circulação por suas ruínas, o coloca em risco a segurança de moradores próximos.

\section{Imagem 4 - Ruínas do Teatro São Pedro (parte interna)}

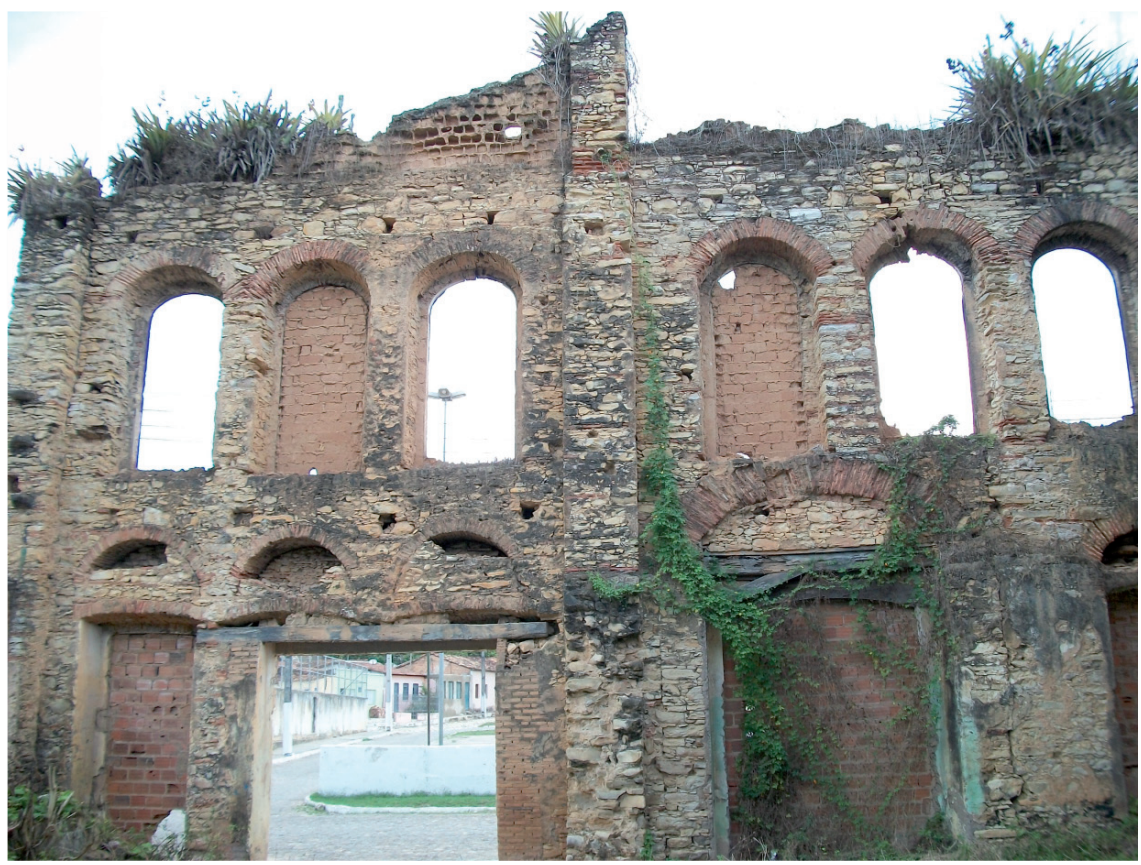

Foto de Janaina Cardoso de Mello (Laranjeiras - SE/Brasil, 24/01/2011)

As ruínas do Teatro São Pedro (fig.3 e 4) estão localizadas na praça Possidônia Bragança, de frente para a Igreja de Nossa Senhora da Conceição dos Pardos, ao lado do prédio da antiga delegacia e que na atualidade está em reforma para abrigar as aulas e laboratórios do curso de Mestrado em Arqueologia da UFS. Não obstante, a obra do teatro tenha sido interrompida, o espaço serviu de palco para a visita de D. Pedro II, acompanhado do Imperatriz D. Tereza Cristina à Laranjeiras na segunda metade do século

${ }^{22}$ SILVA, Eder Donizeti da; NOGUEIRA, Adriana Dantas - Lançando um olhar..., cit, pp. 73-74. 
XIX. Em novembro de 2010 a cidade recebeu o príncipe D. Antonio Orleans e Bragança, bisneto da princesa Isabel, para "redesenhar os passos de seus ancestrais".

Com o surto epidêmico na região e a urbanização do século XX, as tradicionais famílias abastadas migraram para a nova capital Aracaju, fato que promoveu a redução demográfica na cidade. Permaneceram em Laranjeiras a população de baixo poder aquisitivo cujo trabalho se dava nas lavouras de cana-de-açúcar. Sem maiores investimentos monetários oriúndo de particulares ou do governo, a cidade começou a vivenciar um quadro de deterioração do patrimônio arquitetônico. Aventa-se a hipótese de ter sido a difícil condição de sobrevivência econômica o mote que permitiu a sobrevivência das ruínas, mesmo em grande estado de degradação, caso contrário suas fachadas poderiam ter sido cobertas por cerâmicas ou pedrarias eliminando suas caraterísticas originais.

O hospital na rua lateral da Igreja Nossa Senhora Conceição dos $\operatorname{Pardos}^{23}$, destacou-se nos anos iniciais do século XX pela presença em seus quadros do Dr. Antônio Militão de Bragança, nascido em 31 de julho de 1860 em Laranjeiras/SE, filho de Dr. Francisco Alberto de Bragança e Possidônia Maria de Santa Cruz Bragança (origem do nome da praça anteriormente citada, a qual urbanizou com recursos próprios). Formado pela Faculdade de Medicina da Bahia em 1883, clinicou por um tempo no Rio de Janeiro e mais tarde em Alagoas, no município de Pão de Açúcar. Em 1892 regressou a Laranjeiras, sendo empossado em 1898 como Delegado de Higiene. Participou em 1910 da fundação da Sociedade de Medicina de Sergipe e em 1911, atuou no combate ao violento surto de varíola que atingiu Laranjeiras e quase a despovoou com o êxodo de seus moradores para a capital. Desse episódio resultou a escrita do livro "A Varíola em Laranjeiras", com ricos detalhes clínicos, epidemiológicos e profiláticos. Praticou também a oftalmologia e dele se conta, sem comprovação, que teria secretamente prestado atendimento médico a Virgulino Ferreira da

${ }^{23}$ Construída no século XIX, pelos pardos (mestiços), a igreja tornou-se centro de devoção à Nossa Senhora da Conceição. O Imperador Dom Pedro II, na ocasião de sua visita à Laranjeiras, contribuiu com donativos para conclusão das obras. 
Silva, vulgo Lampião, retirando-lhe de um dos olhos um graveto que the havia penetrado acidentalmente ${ }^{24}$.

Mito ou verdade, conta-se que Lampião ${ }^{25}$ teria dado entrada no hospital de Laranjeiras (fig.5) passando-se por um fazendeiro pernambucano e que após recuperar-se do procedimento cirúrgico, teria pago as despesas de um mês de internação e deixado o local furtuitamente durante a madrugada, mas não sem antes registrar com carvão em uma das paredes o recado: "Doutor, o senhor não operou fazendeiro nenhum. O olho que o senhor arrancou foi o do Capitão Virgulino Ferreira da Silva, Lampião". A população de Laranjeiras relata, com certo orgulho, que talvez por esse fato a cidade tenha sido poupada das atitudes violentas que o cangaceiro e seu bando empregaram em outras localidades de Sergipe.

Imagem 5 - Ruínas do Hospital de Laranjeiras

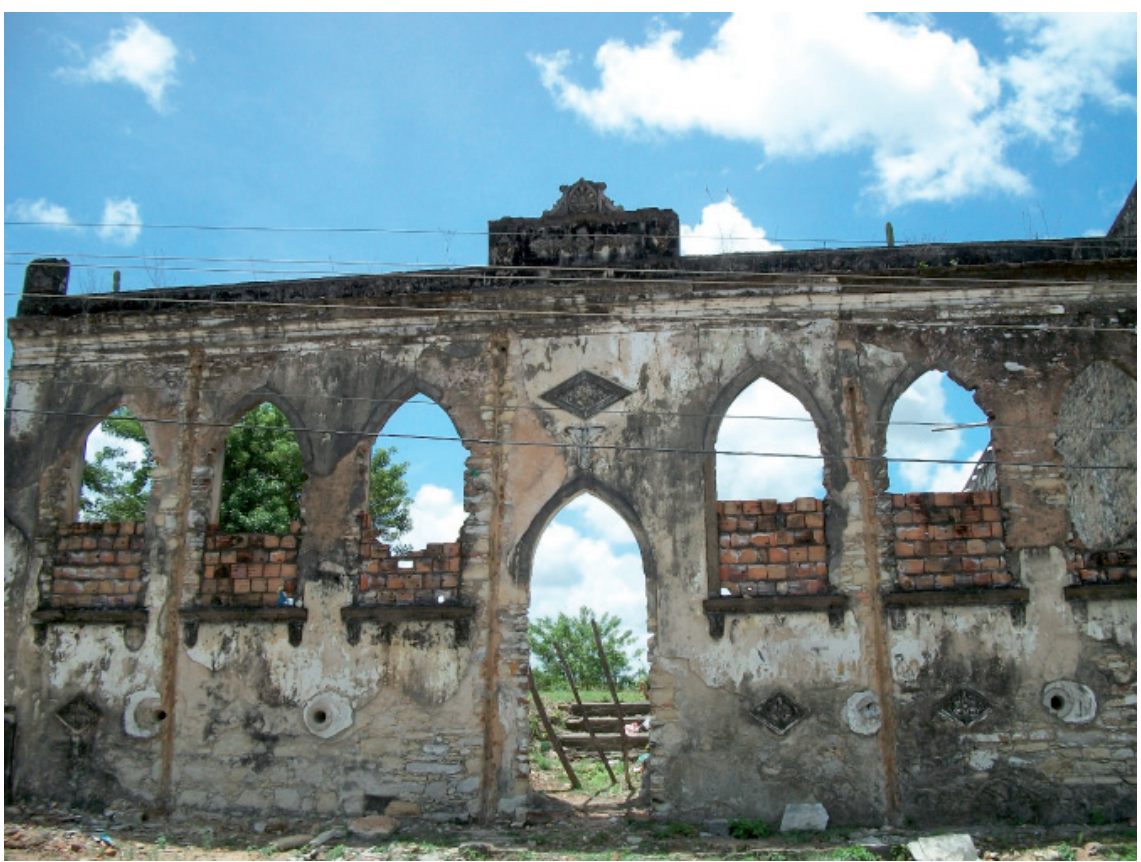

Foto de Janaina Cardoso de Mello (Laranjeiras - SE/Brasil, 24/01/2011)

${ }^{24}$ SANTANA, Antônio Samarone de; DIAS, Lucio Antônio Prado; GOMES, Petrônio Andrade (Orgs.) - Dicionário biográfico de médicos de Sergipe (séc. XIX e XX). Aracaju: ASM, 2009.

${ }^{25}$ Conhecido bandido social do nordeste do Brasil, nas primeiras décadas do século XX. 
Vizinho à loja maçônica do município, o hospital encontra-se hoje em ruínas, abandonado, a conservar somente sua fachada e protegido em sua entrada com uma frágil cerca improvisada com arame farpado e algumas ripas de madeira, por se tratar de uma propriedade particular. Sua arquitetura possui grande variedade estilística européias e nacionais composta por janelas e porta arqueadas, frisos e vários ornamentos em forma de losangos com brasões, flores, além de um entalhe com formato aproximado de um anjo adornando acima da porta da entrada.

Imagem 6 - Detalhe na parte inferior das Ruínas do Hospital de Laranjeiras

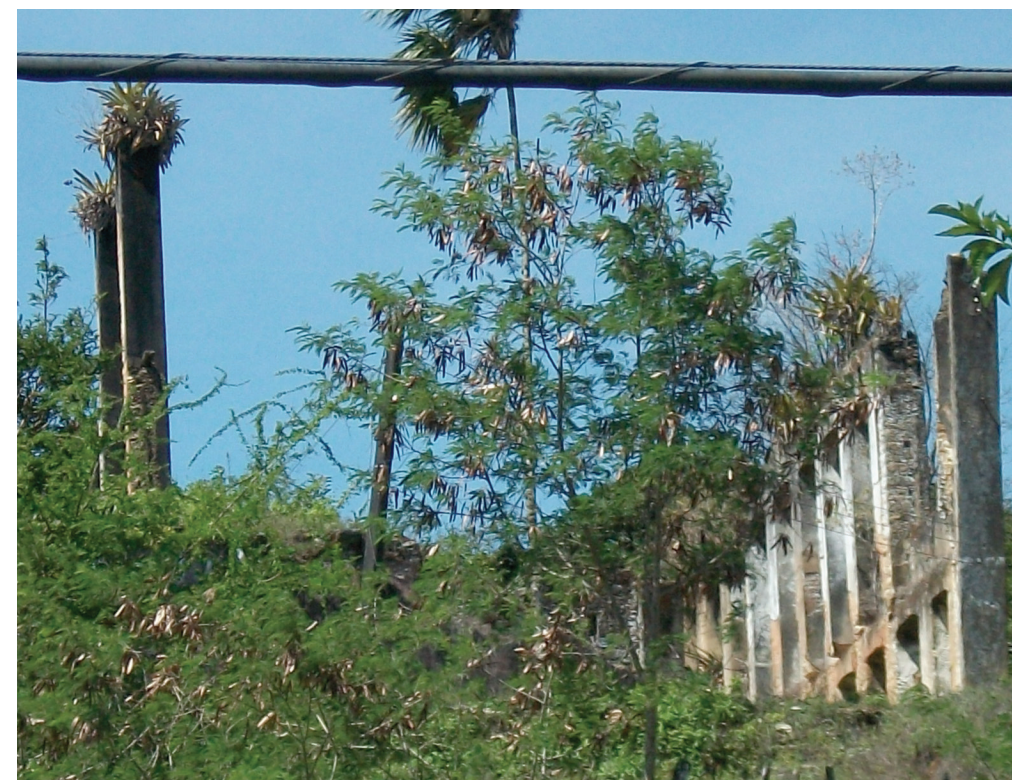

Foto de Janaina Cardoso de Mello (Laranjeiras - SE/Brasil, 24/01/2011)

Na década de 1940 foram procedidas ações de tombamento em Laranjeiras pelo IPHAN que compreenderam a Capela Jesus Maria José do Engenho de igual nome, a Casa do Engenho Retiro, a Igreja de Comandaroba e a Igreja Matriz do Coração de Jesus, como partes de um conjunto arquitetônico marcado pela presença jesuítica do período colonial ${ }^{26}$.

${ }^{26}$ IPHAN - Bens Móveis e Imóveis In: INSTITUTO DO PATRIMÔNIO HISTÓRICO ARTÍSTICO E NACIONAL - Livros de Tombo do Instituto do Patrimônio Histórico e Artístico Nacional. Rio de Janeiro: IPHAN, 1994,pp. 194-195. 
Ainda no século XX, Laranjeiras experimenta a evolução de seu processo de urbanização no quadro de formação da "Grande Aracaju" com a redução das áreas rurais, a ampliação da população urbana com novos modos de viver, no que tange a diversificação das atividades econômicas, o trabalho nos mercados e fábricas, a moradia em conjuntos habitacionais populares, o uso de serviços públicos coletivos.

O conjunto do antigo quarteirão dos Trapiches composto por sobrados residenciais, depósitos de mercadorias e pier onde navios comerciais aportavam, uma construção do século XIX localizada no centro histórico de Laranjeiras, depois de vários anos em ruínas, foi restaurado pelo programa Monumenta em 2009 e hoje comporta o campus da UFS em sua oferta de bacharelados em Museologia, Aqueologia, Arquitetura, Dança e Teatro.

A despeito das obras realizadas no Trapiche, as ruínas abordadas nesse artigo continuaram em seu processo de degradação pela exposição ao tempo e à ausência de um projeto quer fosse de restauração ou consolidação por iniciativa do poder público ou de particulares que detêm algumas das propriedades em questão.

\section{Na arqueologia histórica das ruínas a consolidação como proposta}

O exercício de uma pesquisa interdisciplinar ao articular arqueologia, arquitetura e história poderá informar sobre as formas de ocupação, deslocamento, costumes, conflitos e relações sociais no local.

Segundo Brandi a ruína: "[...] será, pois, tudo aquilo que é testemunho da história humana, mas com um aspecto bastante diverso e quase irreconhecível em relação àquele de que se revestia antes" ${ }^{27}$. Assim, a ruína enquanto alegoria oriunda do fragmento, do incompleto do edifício que não existe mais, contém em si toda a beleza da durabilidade e da fugacidade do vestigío, possuindo algo a dizer, um saber incrustrado em suas pedras e alicerces. Por isso as ruínas aparecem como espaços dignos de rememoração, a implicae a sua conservação e consolidação.

${ }^{27}$ BRANDI, Cesare - Teoria da Restauração. $2^{\text {a }}$ Ed. São Paulo: Ateliê Editorial, 2004, p. 65 . 
Assim explica-se o mote da defesa pela manutenção das ruínas e não de sua restauração. Pois, a diretriz aplicada a sua preservação e conservação, ou seja, da manutenção tais como foram legadas ao presente sob a ação do tempo e a ação depredatória humana, sustenta a tese de uma ação preservacionista atuante e responsável, a mostrar o produto desta relação de uso e de interferência, mediante a clareza desta relação.

Ruins may be ruins; however, whether temple or cathedral, modern railway terminal or ancient marble quarry, irrespective of artistic worth, they must be conserved and 'preserved as found' 28 .

$\mathrm{Na}$ atualidade em Laranjeiras, alguns trabalhos acadêmicos têm sido propostos a partir do questionamento dos projetos de restauração efetivados pelo Monumenta ${ }^{29}$. Multiplicam-se as críticas com relação as escolhas estéticas realizadas na reconstituição arquitetônica, ao uso de materiais inadequados na construção, bem como a ausência de um procedimento de escavação arqueológica com maior durabilidade e rigor. Logo, ao se defender a intenção da manutenção das ruínas como ruínas (reminiscências de um tempo que já não nos pertence mais, a não ser pelos relatos da documentação histórica), adota-se uma perpectiva diferencial que visualiza na consolidação das ruínas a possibilidade de transformá-las em um grande laboratório de estudos avançados sobre a sociedade local e heranças portuguesas constitutivas, levando-se em consideração que para além de uma "remodelagem plástica urbana" a essência da colonização em

28 "Ruínas podem ser as ruínas, no entanto, se templo ou catedral, terminal ferroviário, moderna ou antiga pedreira de mármore, independentemente do valor artístico, devem ser conservadas e 'preservadas como encontrado"'.(Tradução livre da autora) In: ASHURST, John (ed.) - Conservation of ruins. Oxford: Butterworth-Heinemann, 2007, p. 83.

${ }^{29}$ A saber os trabalhos de: BRENDLE, Klaus; BRENDLE, Maria de Betânia U. C. A ausência da Arqueologia Histórica na restauração patrimonial em Laranjeiras. VI Workshop Arqueológico e I Ciclo Internacional de Simpósios Temáticos do Museu de Arqueologia de Xingó: Arqueologia - Integração, Conhecimento e Tecnologia. Campus Laranjeiras UFS, 04 a 09 de outubro de 2010; COSTA, Tatiana de Carvalho - O papel da arqueologia histórica como instrumento de preservação do patrimônio material: o caso da intervenção no "Quarteirão dos Trapiches"de Laranjeiras/SE. Projeto de Mestrado em Arqueologia UFS. Aracaju: 2011. 
meio aos conflitos étnicos e sociais sucitados subsiste em cada pedra daqueles edifícios.

Portanto, a preservação, conservação e manutenção deste bem material, tal como a intervenção humano/temporal o legou a sociedade do presente, é sobretudo uma bandeira de luta fundamental para que não se perca nos emaranhados de cirurgias estéticas arquitetônicas ou de esquecimentos induzidos a sua distinta posição num determinado momento histórico sergipano e brasileiro.

Várias técnicas podem ser usadas para registrar as informações da ruína existente, desde o estudo dos materiais utilizados na edificação, das pigmentações originais das paredes, datação da construção a partir de escavações arqueológicas, registros fotográficos tomados do edifício, com seus detalhes e arredores, filmagens, desenhos arquitetônicos e até elaboração de maquetes em 3D. Também deve-se considerar que:

Ruins of all these building types remain throughout the country and are an important part of our national heritage. While they have survived, sometimes for hundreds of years, they will not survive indefinitely without periodic care and attention. Ruins are buildings that no longer have their original defences against the elements, such as roofs, windows and doors, while the loss of floors, parts of walls and other fabric may have altered or weakened their structural integrity ${ }^{30}$.

As intervenções para consolidação das ruínas no entanto devem ser precedidas por um diagnóstico exaustivo de anomalias estruturais, a utilizar-se de técnicas pouco invasivas como a termografia ou a velocidade de propagação de ultrasons para avaliar a integrinidade das construções ${ }^{31}$.

30 "Ruínas de todos estes tipos de construção continuam em todo o país e são uma parte importante do nosso património nacional. Apesar de terem sobrevivido, às vezes centenas de anos, elas não vão sobreviver indefinidamente sem cuidado e atenção periodicamente. Ruinas são os edifícios que já não têm as suas defesas contra os elementos originais, como telhados, janelas e portas, enquanto a perda de pisos, paredes e peças de outro tecido pode ter alterado ou enfraquecido a sua integridade estrutural" (Tradução livre da autora) In: GOVERNMENT OF IRELAND - Ruins - The Conservation and repair of Masonry Ruins. Dublin: The Stationery Office, 2010, p. 12.

${ }^{31}$ PINHO, Fernando F.S; Baião, Manuel F.C.; LÚCIO, Válter J.G - Técnicas de consolidação de paredes de edifícios antigos. In: Actas $3^{\circ}$ Encore. Lisboa: LNEC, 2003, p. 467. 
Posterioremente, a adoção de medidas de proteção como a utilização de coberturas temporárias procura evitar a deterioração acelerada das paredes e madeiras, até que um cuidadoso plano de consolidação elaborado por especialistas seja posto em prática. Os cuidados devem ser tomados para garantir medidas temporárias que evitem maiores danos causados pela ação do vento e da chuva, sem contudo "eternizarem-se" em função da falta de investimentos do poder público ou privado. Nesse sentido a iniciativa da UFS e de setores organizados da sociedade civil em Laranjeiras são essenciais ao processo, para que não sejam apenas observadores passivos mas sim protagonistas de uma atitude de preservação do patrimônio da cidade.

O escoramento da estrutura também pode ser necessário para evitar o desabamento de paredes, telhado ou andares. Um engenheiro estrutural será imprescindível para avaliar e propor a retenção temporária de emergência se necessário, no entanto tudo o que é proposto deve ser reversível e discutido com as respectivas autoridades responsáveis pelas homologações das atividades de salvaguarda realizadas.

No cuidado e conservação dos ruínas, o arqueólogo será essencial para agregar valor aos vestígios de grupos subordinados, evitando que sejam esquecidos e protegendo-os contra visitação pública e exploração científica inadequadas, uma vez que os elementos da cultura material ali encontrados podem adicionar novas informações ao conhecimento do local, que não se perdeu. Assim: "uma das razões que permitem que questões sociais possam ser abordadas a partir de estruturas arquitetônicas refere-se à descoberta, de que elas podem ser 'lidas' da mesma forma que os estratos arqueológicos do solo" 32 .

Desse modo, as escavações para drenagem e as fundações devem possuir um acompanhamento arqueológico para garantir que técnicas inapropriadas sejam evitadas e para registrar todos os itens descobertos durante a escavação, a pesquisa e/ou da reintegração do que foi encontrado e removido para análise. Acima das estruturas do solo os métodos do arqueólogo irão registrar o desenvolvimento histórico e as origens de uma construção, recuperar dados, catalogar e higienizar os objetos, validar propostas e criar suportes para a consolidação do sítio arqueológico. Esses estudos podem

\footnotetext{
${ }^{32}$ ORSER Jr., C.E - Introdução à...cit, p. 37.
} 
fornecer informações valiosas sobre o conhecimento dos períodos anteriores, assim como das relações sociais e de produção que se desenvolviam nesse espaço.

Uma atenção especial deve ser dada aos procedimentos de garatia da saúde e segurança tanto dos trabalhadores e pesquisadores, quanto da população que reside próxima a essas ruínas. Devem ser instaladas barreiras e avisos de "Estrutura Perigosa" de caráter público e com boa visibilidade sempre que necessário. No plano global de ação de risco, avaliações devem ser feitas e o local deve ser mantido seguro para todo o pessoal visitar, mesmo em estágios iniciais.

Onde as paredes são recém-escavadas e não há nenhum plano para cobri-los ou aterramento, medidas de proteção devem ser tomadas para minimizar danos causados pela secagem. A drenagem pode danificar a superfície maciça e as tonalidades com a cristalização repetida de sais solúveis nos poros da argamassa, pedra e gesso, e até mesmo em tijolos expostos nas proximidades provocados pelos ciclos de molhagem e secagem. Por isso, até que a ruína seja estabilizada são necessárias proteções temporárias com folhas de geotêxtil ${ }^{33}$ e areia para o reforço das edificações ${ }^{34}$.

Um cuidado especial deve ser dado a vegetação que se enraíza nas paredes e telhados como as trepadeiras e árvores que podem corroer e desestabilizar o núcleo de construções em alvenaria. Sua remoção deve ser precedida de uma catalogação da espécie dentro dos parâmetros da legislação ambiental vigente, com atenção para evitar-se mais danos a estrutura já corrompida.

As raízes, especialmente a hera, com caules que engrossam rapidamente podem abrir as articulações prediais. Sendo a erradicação dessa vegetação já estabelecida de difícil trato e por isso a necessitar de estudos especializados para viabilizar soluções.

Um estudo completo deve ser realizado por consultores especializados para explorar plenamente a viabilidade das propostas de consolidação de ruínas frente ao desejo de se conservar o máximo do patrimônio local em Laranjeiras. Todavia, sem abdicar de ao se conservar as ruínas do

${ }^{33}$ Geotêxtil não-tecido, fabricado $100 \%$ com fibras sintéticas, para aplicação em obras de drenagem, filtração, separação e reforço de solos, atua como elemento com excelentes características mecânicas e hidráulicas.

${ }^{34}$ LIND, Tuija - How to treat ruins? BLF/NFB Conference. Greenwich: s/e, 2007. 
tempo passado manter um contínuo diálogo dessas edificações com a contemporaneidade e demandas sociais da população que a cerca.

\section{Considerações Finais}

A pesquisa arqueológica histórica, cada vez mais tem atuado no sentido de estabelecer conexões com a população local, aproximando as instituições acadêmicas das pessoas comuns, inteirando-a do papel dos vestígios do passado também como um retrato do presente a abrir janelas para um patrimônio coletivo gerador de benefícios coletivos, sejam econômicos, sociais, políticos ou culturais.

Uma população que tem domínio das informações aprende a importância da salvaguarda, preservação e promoção do patrimônio cultural, ao adquir ferramentas para reivindicar seus direitos junto às instâncias competentes, além de valorizar os espaços de reconstituição e afirmação de sua identidade cultural.

Frente aos esquecimentos da contemporaneidade imersa na velocidade das transformações da pós-modernidade, as ruínas de cidades históricas como Laranjeiras sofrem depredações pela ação do tempo ou por banalizações humanas individuais ou institucionais (demolição ou restauração). O estudo da cultura material na perspectiva da linha da arqueologia histórica lança novos olhares sobre a sociedade moderna e por esse viés pode-se reconstituir e compreender a relação dos grupos com o ambiente social e urbano que o cerca ao longo dos tempos. 